\section{PERBEDAAN KOMITMEN IBU \\ DALAM PEMBERIAN \\ IMUNISASI DPT 2 PADA BAYI \\ USIA DIBAWAH 3 BULAN \\ SEBELUM DAN SESUDAH \\ PEMBERIAN HEALTH \\ PROMOTION MODEL NOLA J., PANDER}

\section{DIFFERENCES OF MOTHER COMMITMENT TO GIVING DPT \\ 2 IMMUNIZATION FOR A BABY AGE UNDER 3 MONTHS \\ BEFORE AND AFTER \\ PROVIDING HEALTH \\ PROMOTION MODEL NOLA J., PANDER}

\author{
Agus Priyanto*) \\ Mulia Mayangsari*)
}

*) Sekolah Tinggi Ilmu Kesehatan (STIKes) Ngudia Husada Madura

ABSTRACT
Parent's commitment to immunizing her
toddler is one of the obstacles to achieving the
success of the immunization coverage target.
Immunization itself is very important as an effort to
prevent disease in children and has been
recommended to the community. Based on
preliminary study results, researchers conducted
interviews with local midwives obtained data there
are some children who have not immunized DPT 2 it
is strengthened by interviews with 10 mothers who
do not immunize DPT 2 on the baby for fear of side
effects. The aim of this research is to know the
difference of mother's commitment before and after
giving Health Promotion Model Nola J.Pander.
This research used one group design pre post test
design. With two variables, independent variables
are health education, dependent variable of mother's
commitment. The data collection used questionaire,
data taken from respondent such as mother with
population of 44 responden with amount the sampel
counted 30 mother were taken with simple random
sampling technique, at Burneh community health
center. The results were analyzed descriptively and
correlated using the Wilcoxon Match Pairs Test
The results were analyzed descriptively and
correlated using the Wilcoxon Match Pairs Test test.
Analysis of Wilcoxon Match Pairs Test with p value =
0.000 so H1 accepted means there are differences
before and after health education with Nola J.Pander
approach.
There are still several other factors that influence the
commitment, among others, family and cultural
factors that are not examined in this study, so that
the next researcher is expected to do research on
the influence of these factors on the mother's
commitment
Key words: Parent's commitment, Health Promotion
Model Nola J. Pander

Correspondence : Agus Priyanto, Jl. R.E. Martadinata Bangkalan, Indonesia.

\section{PENDAHULUAN}

Pemerintah dan masyarakat melakukan berbagai kegiatan upaya kesehatan untuk memelihara dan meningkatkan kesehatan. Dalam mewujudkannya bisa ditinjau dari kegiatan pemeliharaan kesehatan dan kegiatan peningkatan kesehatan.
Kegiatan peningkatan kesehatan yang dimaksud terdiri dari aspek promotif dan aspek preventif, sedangkan kegiatan pemeliharaan kesehatan meliputi aspek kuratif dan aspek rehabilitative (Notoatmodjo, 2012). Kegiatan preventif yang bisa dilakukan dan akan sangat efektif 
untuk menghidari terpaparnya suatu penyakit infeksi dengan dilakukannya imunisasi

Imunisasi merupakan rangkaian kegiatan yang terprogram dengan cara memasukkan antigen tertentu dengan kadar yang lemah kedalam tubuh agar tubuh bisa menstimulasi daya tahan tubuh yang akan dikeluarkan sehingga tubuh mampu resisten terhadap penyakit tertentu, hal ini diharapkan untuk meminimalisir munculnya laporan kejadian penyakit, kecacatan serta kematian yang ditimbulkan (Deslidel, 2011).

Dewasa ini imunisasi dioptimalkan oleh pemerintah untuk mencegah penyakit dan mengurangi adanya laporan penyakit disertai kematian anak karena Penyakit yang Dapat Dicegah dengan Imunisasi (PD3I), seperti, Hepatitis B, Campak, Polio, Radang selaput otak dan paru, sedangkan Imunisasi DPT merupakan rangkaian program intervensi kesehatan dari pemerintah yang diberikan untuk mencegah terjangkitnya penyakit infeksi seperti Difteri, Pertusis dan Tetanus.

Sampai saat ini kurang lebih 1,4 juta anak didunia dilaporkan meninggal setiap tahunnya dikarenakan berbagai penyakit yang didasari dengan tidak dilakukannya imunisasi. Kasus difteri di Indonesia menjadi fenomena masalah kesehatan yang menjadi basis lingkungan yang tersebar di seluruh dunia (Depkes RI, 2013) . Kejadian difteri di Indonesia pada tahun 2011 menjadikan Indonesia sebagai negara Asia Tenggara dengan kasus difteri tertinggi bahkan indonesia menempati peringkat kedua dengan 806 laporan kejadian difteri setelah India di peringkat pertama dengan jumlah laporan kejadian difteri 3485 dan Negara Nepal yang berada diperingkat ketiga dengan laporan kejadian kasus sebanyak 94 kasus (WHO, 2012). Kasus difteri yang terjadi di Indonesia telah menjamah sampai ke 18 provinsi dengan laporan 38 orang meninggal dunia tidak terkecuali di Jawa Timur. Banyaknya kasus difteri di Jawa Timur, menjadikan provinsi Jawa Timur dinobatkan sebagai Provinsi dengan Kejadian Luar Biasa (KLB) difteri karena mengalami peningkatan yang signifikan terhadap laporan kejadian adanya kasus difteri sampai mengakibatkan kematian setiap tahunnya yang tersebar di hampir seluruh kabupaten/kota yang ada di Provinsi Jawa Timur (Depkes RI, 2013).

Kabupaten atau Kota
Bangkalan pada tahun 2017 mengalami laporan kenaikan jumlah kasus difteri sebanyak 19 orang yang sebelumnya pada tahun 2016 sebanyak 11 laporan kasus yang terdeteksi di beberapa kecamatan, sementara bila dilihat dari pencapaian imunisasi dasar lengkap tahun 2017 sebanyak 11,567 (77,57\%). Laporan capaian ini apabila dibandingkan pada tahun sebelumnya yaitu pada tahun 2016 capaian imunisasi dasar lengkap dengan persentase $88 \%$ (Dinas Kesehatn Kabupaten Bangkalan, 2017).

Berdasarkan hasil studi pendahuluan pada bulan Februari 2018, peneliti melakukan blusukan dan melakukan wawancara dengan bidan setempat dan didapatkan data bahwa masih adanya beberapa anak yang belum dilakukan pemberian imunisai DPT 2, keadaan ini menjadi relevan ketika peneliti melakukan wawancara kepada $10 \mathrm{ibu}$ yang tidak 
melakukan imunisasi lanjutan DPT 2 pada bayinya didapatkan hasil 7 orang mengeluhkan takut mengimunisasikan anaknya kembali karena anak menjadi rewel setelah disuntik atau dilakukan imunisasi sebelumnya, bahkan 3 ibu dengan polosnya menyatakan pemberian imunisasi kurang penting dan bermanfaat untuk bayinya sehingga mereka tidak ada inisiatif untuk kembali melakukan imunisasi kepada anaknnya.

Keadaan ini sebenarnya sudah dibenahi oleh petugas kesehatan setempat hanya saja tindak lanjut yang dilakukan kurang optimal, hal ini dibuktikan dengan peran petugas yang tidak melakukan blusukan dan edukasi secara langsung kerumah masyarakat yang terdeteksi anaknya belum melakukan imunisasi lanjutan, petugas kesehatan hanya melakukan pendidikan kesehatan pada saat kegiatan program dimana posyandu itu berlangsung, padahal banyak sekali orang tua yang tidak hadir saat kegiatan tersebut.

Komitmen seseorang dalam melakukan tindakan preventif atau pencegahan biasa dipengaruhi oleh faktor, pendidikan seseorang dan pengetahuan seseorang. Tingkat pendidikan masyarakat yang rendah serta kurangnya pengetahuannya tentang penyakit, manfaat dilakukannya imunisasi dan bahaya komplikasinya menjadi faktor utama penyebab rendahnya komitmen masyarakat dalam merencanakan tindakan untuk pencegahan penyakit. Beberapa factor lain yang mempengaruhi ibu sehingga ibu kurang pro aktif terhadap pemberian imunisasi ialah adanya kondisi sosio demografi yang bervariasi, ketepatan waktu pelayanan imunisasi, promosi kesehatan, dan faktor ekonomi (Depkes RI, 2013). Ketidakpatuhan orang tua dalam mengimunisasikan anaknya akan berdampak terhadap kurang optimalnya capaian program pemerintah untuk peningkatan derajat kesehatan masyarakat dengan meningkatnya angka kesakitan dan angka kematian akibat penyakit difteri, pertusis dan tetanus, (Kemenkes, 2014)

Kegiatan atau pelaksanaan Imunisasi itu sangat penting sebagai langkah awal untuk mencegah hadirnya penyakit yang bisa terjadi pada anak. Program kegiatan ini sudah direkomendasikan pada masyarakat sudah sejak lama hanya saja sampai saat ini capaian target cakupan imunisasi pada anak masih kurang sesuai harapan yaitu dengan cakupan imunisasi dengan presentase 80-100\%. Guna meningkatkan komitmen orang tua dengan kesadaran dan keaktifan kelengkapan imunisasi dasar maka diperlukannya upayayang jauh lebih optimal dari petugas kesehatan dengan melakukan pemberian konseling dan pendidikan kepada keluarga (Achmadi, 2006)

Pengetahuan tentang kesehatan dapat ditingkatkan dengan berbagai upaya, salah satunya adalah dilakukannya pendidikan kesehatan, pendidikan kesehatan erat hubunganya dengan pencegahan penyakit, dengan dilakukannya pendidikan kesehatan orang tua diharapkan mampu menentukan pilihan dalam pengambilan arah keputusan yang terkait dengan kesehatan (Susilo, 2011)

Teori konsep model keperawatan Health Promotion yang dipelopori dan dikembangkan oleh Pander, merupakan konsep model teori pengharapan yang bisa memperdayakan individu dan 
keluarga dalam meningkatkan capaian derajat kesehatan, penyampaian yang positif terhadap keluarga melalui pendidikan kesehatan dapat meningkatkan pengetahuan dan kepercayaan diri keluarga serta bisa mengarahkan keluarga dalam pengambilan keputusan tentang pilihan kesehatan yang akan diambil. Konsep ini menggambarkan hubungan antar manusia dengan lingkungan fisik, interpersonal didalam berbagai rangkaian dimensi. Model ini menyatukan teori nilai pengharapan dan teori pembelajaran sosial dalam tinjauan perspektif keperawatan manusia bisa dilihat dari fungsi secara holistik, konsep ini mampu memberdayakan invidu bahwa keadaan sakit merupakan kondisi yang membutuhkan biaya yang tidak sedikit sedangkan perilaku promosi kesehatan merupakan keadaan logis dan jauh lebih ekonomis. Model ini terbagi menjadi tiga variabel yang ikut berpengaruh dalam perilaku kesehatan antara lain sikap yang berhubungan dengan aktivitas, Komitmen dalam merencanakan tindakan serta adanya kebutuhan yang mendesak (Tomey Alligood, 2006 dalam Rahmawati 2012). Dengan mengoptimalkan upaya pembelajaran pengembangan konsep teori konsep model keperawatan yang tepat maka diharapkan pengetahuan seseorang berubah sehingga memiliki komitmen disertai sikap dan perilaku kesehatan sesuai dengan capaian yang diharapkan.

\section{METODE PENELITIAN}

Penelitian merupakan penelitian analitik dengan pendekatan korelasi sampel 30 orang dengan teknik simple random sampling. Variabel independen pendidikan kesehatan

variabel dependen komitmen ibu yang dilakukan dengan pengumpulan data menggunakan kuesioner dengan uji wilcoxon

\section{HASIL PENELITIAN}

a. Karakteristik berdasarkan Jenis Kelamin

Tabel 4.1 Distribusi frekuensi berdasarkan jenis kelamin anak di Puskesmas Burneh

\begin{tabular}{|c|c|c|}
\hline $\begin{array}{c}\text { Jenis } \\
\text { Kelamin } \\
\text { Anak }\end{array}$ & $\begin{array}{l}\text { Frekuensi } \\
\text { (f) }\end{array}$ & $\begin{array}{c}\text { Persentase } \\
(\%)\end{array}$ \\
\hline Laki laki & 17 & 56.7 \\
\hline $\begin{array}{c}\text { Perempua } \\
n\end{array}$ & 13 & 43.3 \\
\hline Jumlah & 30 & 100 \\
\hline $\begin{array}{l}\text { Sumber: } \\
\text { Berdas } \\
\text { diketahui } \\
\text { responden } \\
\text { laki yaitu se } \\
\% \text { ) }\end{array}$ & $\begin{array}{l}\text { ta primer } 2 \\
\text { kan ta } \\
\text { hwa seba } \\
\text { erjenis ke } \\
\text { anyak } 17\end{array}$ & 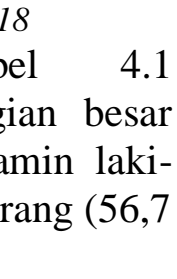 \\
\hline
\end{tabular}

b. Karakteristik responden berdasarkan Pendididkan

Tabel 4.2 Distribusi frekuensi berdasarkan pendidikan orang tua di Puskesmas Burneh

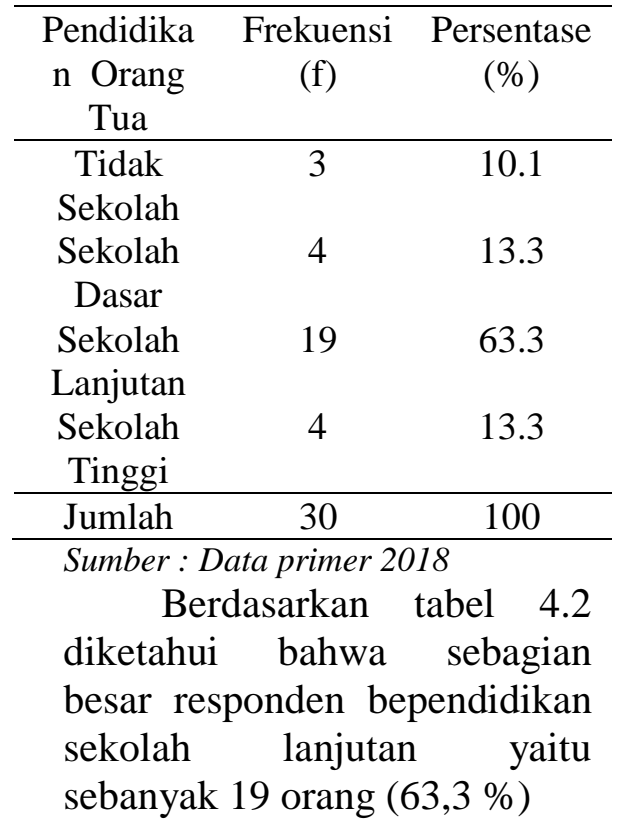


c. Karakteristik

responden

berdasarkan Pendididkan

Tabel 4.3 Distribusi frekuensi berdasarkan pekerjaan orang tua di Puskesmas Burneh

\begin{tabular}{ccc}
\hline $\begin{array}{c}\text { Pekerjaan } \\
\text { Orang } \\
\text { Tua }\end{array}$ & $\begin{array}{c}\text { Frekuensi } \\
\text { (f) }\end{array}$ & $\begin{array}{c}\text { Persentase } \\
(\%)\end{array}$ \\
\hline Tidak & 14 & 46.7 \\
Bekerja & 9 & 30.0 \\
Swasta & 6 & 20.0 \\
PNS & 1 & 3.3 \\
Lainnya & & \\
\hline Jumlah & 30 & 100 \\
\hline
\end{tabular}
Sumber : Data primer 2018

Berdasarkan tabel 4.3 diketahui hampir setengahnya responden tidak bekerja (Ibu Rumah Tangga) yaitu sebanyak 14 orang $(46,7 \%)$

\section{DATA KHUSUS}

a. Distribusi Frekuensi Berdasarkan Komitmen responden sebelum pendidikan kesehatan

Tabel 4.4 Distribusi frekuensi komitmen ibu sebelum dilakukan pendidikan kesehatan

\begin{tabular}{ccc}
\hline $\begin{array}{c}\text { Kriteria } \\
\text { Skoring }\end{array}$ & $\begin{array}{c}\text { Frekuensi } \\
(\mathrm{f})\end{array}$ & $\begin{array}{c}\text { Persentase } \\
(\%)\end{array}$ \\
\hline Baik & 16 & 53.3 \\
Cukup & 13 & 43.3 \\
Kurang & 1 & 3.3 \\
\hline Jumlah & 30 & 100 \\
\hline \multicolumn{2}{l}{ Sumber : Data primer 2018 }
\end{tabular}

Berdasarkan tabel 4.4 diketahui bahwa sebagian besar responden memiliki komitmen yang baik yaitu sebanyak 16 orang (53\%) b. Distribusi Frekuensi Berdasarkan Komitmen responden sesudah pendidikan kesehatan

Tabel 4.5 Distribusi frekuensi komitmen ibu sesudah dilakukan pendidikan kesehatan

Kriteria Frekuensi Persentase

\begin{tabular}{ccc} 
Skoring & (f) & $(\%)$ \\
\hline Baik & 28 & 93.3 \\
Cukup & 2 & 6.7 \\
Kurang & 0 & 0 \\
\hline Jumlah & 30 & 100 \\
\hline Sumber: Data & primer 2018
\end{tabular}
Sumber : Data primer 2018

Berdasarkan tabel 4.5 hampir seluruh responden memiliki komitmen yang baik yaitu sebanyak 28 orang $(93,3 \%)$

c. Frekuensi sebelum dan sesudah pendidikan kesehatan

Tabel 4.6 Pengaruh Pendidikan Kesehatan Terhadap Komitmen Responden Untuk Mengimunisasikan Anaknya

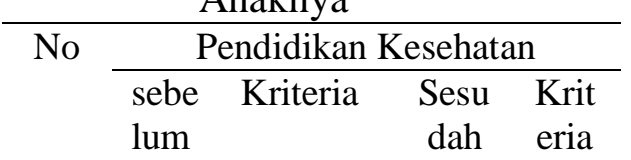




\begin{tabular}{|c|c|c|c|c|}
\hline 1 & 30 & Cukup & 35 & Baik \\
\hline 2 & 30 & Cukup & 32 & Baik \\
\hline 3 & 32 & baik & 35 & Baik \\
\hline 4 & 35 & Baik & 35 & Baik \\
\hline 5 & 30 & Cukup & 36 & Baik \\
\hline 6 & 31 & Baik & 35 & Baik \\
\hline 7 & 25 & Cukup & 33 & Baik \\
\hline 8 & 26 & Cukup & 31 & Baik \\
\hline 9 & 33 & Baik & 35 & Baik \\
\hline 10 & 32 & Baik & 38 & Baik \\
\hline 11 & 32 & Baik & 35 & Baik \\
\hline 12 & 27 & Cukup & 36 & Baik \\
\hline 13 & 35 & Baik & 38 & Baik \\
\hline 14 & 20 & Kurang & 25 & Cuk \\
\hline 15 & 25 & Cukup & 38 & up \\
\hline 16 & 35 & Baik & 38 & Baik \\
\hline 17 & 33 & Baik & 36 & Baik \\
\hline 18 & 35 & Baik & 38 & Baik \\
\hline 19 & 27 & Cukup & 36 & Baik \\
\hline 20 & 32 & Baik & 36 & Baik \\
\hline 21 & 34 & Baik & 38 & Baik \\
\hline 22 & 35 & Baik & 37 & Baik \\
\hline 23 & 35 & Baik & 37 & Baik \\
\hline 24 & 23 & Cukup & 35 & Baik \\
\hline 25 & 23 & Cukup & 37 & Baik \\
\hline 26 & 33 & Baik & 37 & Baik \\
\hline 27 & 25 & Cukup & 35 & Baik \\
\hline 28 & 22 & Cukup & 38 & Baik \\
\hline 29 & 33 & Baik & 37 & Baik \\
\hline 30 & 25 & Cukup & 27 & $\begin{array}{c}\text { Baik } \\
\text { cuk }\end{array}$ \\
\hline \multicolumn{3}{|c|}{$\begin{array}{c}\text { f tertinggi }=\text { Baik } \\
\quad a=0,05\end{array}$} & \multicolumn{2}{|c|}{$\begin{array}{c}\mathrm{f} \text { tertinggi }= \\
\text { Baik } \\
\mathrm{p}=0,000\end{array}$} \\
\hline
\end{tabular}

Berdasarkan tabel 4.6 diketahui bahwa frekuensi tertinggi komitmen sebelum dilakukan pendidikan kesehatan sebagian besar memiliki komitmen baik dan frekuensi tertinggi komitmen ibu sesudah dilakukan pendidikan kesehatan hampir seluruhnya adalah baik (93,3 $\%$ ). Berdasarkan uji statistik dengan menggunakan uji Wilcoxon diperoleh hasil negative ranks yaitu $\mathrm{N}=0$ yang berarti tidak ada penurunan komitmen sesudah dilakukan pendidikan kesehatan sedangkan pada positive ranks didapatkan nilai $\mathrm{N}=29$ yang berarti 29 responden mengalami peningkatan komitmen sesudah dilakukan pendidikan kesehatan, dan hanya 1 orang yang nilainya tetap (ties). Dari hasil uji statistik juga diperoleh nilai $\mathrm{p}=$ 0,000 sehingga $\mathrm{p}$ value $<\alpha=0,05$ sehingga $\mathrm{H} 1$ diterima yang berarti ada perbedaan komitmen ibu sebelum dan setelah dilakukan pemberian pendidikan kesehatan melalui pendekatan Nola J., Pander.

\section{PEMBAHASAN}

\section{Komitmen orang tua sebelum diberikan pendidikan kesehatan}

Hasil penelitian menunjukkan bahwa sebagian besar responden memiliki komitmen yang baik yaitu sebanyak 16 orang (53\%), namun masih terdapat 13 orang responden yang komitmennya cukup bahkan masih ada 1 orang responden yang memiliki komitmen yang kurang.

Berdasarkan hasil analisa peneliti komitmen yang baik yang dimiliki responden adalah bentuk keberhasilan yang dilakukan oleh semua pihak termasuk petugas kesehatan setempat dalam memberikan influence yang baik bagi masyarakat di wilayah puskesmas Burneh, selain itu perkembangan media dan tehnologi yang memudahkan penyebaran informasi mampu memberikan dampak baik bagi perubahan pemahaman kesehatan masyarakat. Masyarakat dapat dengan mudah mengakses informasi tentang manfaatnya dan dampak dari pemberian imunisasi sehingga tidak mengherankan jika jumlah komitmen yang baik sudah ada pada responden yang diteliti, namun demikian masih 
terdapat beberapa responden yang memiliki komitmen yang cukup bahkan satu orang masih kurang. Sedangkan komitmen yang kurang dimiliki oleh responden no 14 dengan total skor 20, responden ini lebih banyak menjawab pernyataaan dengan jawaban kurang setuju pada masing masing item pernyataan yang diajukan untuk menunjukkan komitmennya, sehingga pada saat tabulasi diketahui bahwa komitmen responden ini adalah kurang

Salah satu faktor terkait yang bisa mempengaruhi komitmen ibu adalah faktor pendidikan, hasil penelitian menunjukkan bahwa tingkat pendidikan seseorang mempengaruhi cara pandang dan pemahaman seseorang mengenai imunisasi. sebagian responden memahami bahwa anak nya yang lain juga tidak pernah mendapatkan imunisasi sebelumnya namun masih sehat sehingga ibu menganggap imunisasi bukanlah hal yang penting, apalagi ada efek panas sehabis di imunisasi menyebabkan ibu ini lebih memilih mempunyai komitmen yang kurang untuk melakukan imunisasi. Sedangkan responden yang memiliki komitmen cukup, pernyataan kurang setuju dipilih oleh semua responden terdapat pada item pertanyaan no 9 tentang efek dari imunisasi, mereka masih mengangap efek itu tidak wajar karena reaksi rewel pada bayi yang hanya bisa menangis, telah membuat responden trauma dan takut dengan imunisasi. Sedangkan untuk responden yang memiliki komitmen cukup yaitu sebanyak 13 orang, pengalaman imunisasi sebelumnya telah menjadi dorongan bagi ibu untuk melakukannya, namun khusus untuk imunisasi DPT, efek panas yang harus terjadi akibat efek samping penyuntikan masih menimbulkan trauma bagi ibu.

Komitmen diartikan sebagai intensi atau niat untuk melakukan perilaku kesehatan tertentu, termasuk identifikasi strategi untuk dapat dengan baik melakan tindakan (Pander, N.J, Murdaugh, C.L., \& Parsons, M.A dalam Alligood \& Tomey, (2006)). Seseorang berperilaku karena adanya faktor keinginan, kesengajaan, atau karena memang sudah direncanakan. Niat berperilaku masih merupakan suatu rencana yang belum diaplikasikan. Oleh sebab itu mengidentifikasi komitmen di awal adalah perlu untuk menilai niat dan kemauan sesorang melak ukan tindakan yang dimaksud.

Hal ini sesuai dengan pernyataan Notoadmojo (2012) bahwa pendidikan kesehatan merupakan suatu kegiatan intervensi yang diberikan kepada suatu individu atau kelompok sehingga perilaku individu dan kelompok sesuai dengan nilai, nilai kesehatan yang diharapkan. Seseorang yang memiliki pengetahuan dan kadar informasi tentang kesehatan yang luas maka orang tersebut akan bersikap, berprilaku serta patuh dalam melaksanakan program kesehatan yang didapatkannya (Perry and Potter, 2009).

Pengalaman serta pemahaman yang salah mengenai imunisasi yang dimiliki ibu mempengaruhi komitmen ibu selanjutnya, informasi yang terbatas atau informasi yang salah dimengerti juga telah turut mempengaruhi perilaku ibu dalam mengimunisasikan anaknnya. 


\section{Komitmen orang tua sesudah diberikan pendidikan kesehatan}

Hasil penelitian menunjukkan data sebagian besar responden memiliki komitmen yang baik yaitu sebanyak 28 orang $(93,3 \%)$ dan hanya 2 orang saja $(6,7 \%)$ yang memiliki komitmen yang cukup.

Dari hasil analisa peneliti diketahui terdapat perubahan yang signifikan pada respon ibu untuk mengimunisasikan anaknya, perubahan kognisi yang terbentuk setelah pemberian pendidikan kesehatan telah berdampak pada perubahan komitmen responden untuk mau mengimunisasikan anaknya. Keluarga, kelompok dan pemberi layanan kesehatan adalah sumber interpersonal penting yang bisa mempengaruhi, meningkatkan atau meminimalkan keinginan untuk berperilaku promosi kesehatan. Selain itu pengaruh situasi lingkungan eksternal juga bisa memicu dalam meningkatkan atau meminimalkan keinginan untuk berpartisipasi terhadap keikutsertaan perilaku promosi kesehatan.

Oleh sebab itu pendidikan kesehatan yang diberikan petugas kesehatan adalah influence yang baik untuk menambah partisipasi masyarakat akan sebuah komitmen kesehatan.namun demikian masih terdapat 2 orang yang memiliki komitmen yang cukup yaitu responden no 14 dan 30. Responden no 14 sebelum pendidikan kesehatan mempunyai komitmen kurang, namun setelah diberikan pendidikan kesehatan mampu memiliki komitmen yang cukup untuk mengimunisasikan anaknya. Sedangkan responden no 30 sebelum pendidikan kesehatan memiliki komitmen yang cukup dan setelah pendidikan kesehatan komitmennya tetap cukup. Namun nilai tabulasi berubah dari total 25 menjadi 27 karena responden mengubah pilihan pada item pertanyaan no 10 dari semula tidak setuju menjadi setuju pada pernyataan bahwa pemberian imunisasi akan memberi dampak terhadap pertumbuhan dan perkembangan anak.

Niat bukan merupakan suatu perilaku, sedangkan perilaku merupakan suatu bentuk tindakan nyata yang dilakukan atau dikerjakan. Komitmen yang tinggi untuk berperilaku tertentu sesuai rencana, meningkatkan kemampuan individu untuk mempertahankan perilaku promosi kesehatannya sepanjang waktu.

Pander menyatakan bahwa komitmen dengan rencana tindakan (pencegahan) atau Commitmen to plan of action menggambarkan konsep tentang keinginan dan identifikasi strategi yang terencana yang mendukung implementasi perilaku kesehatan. Seseorang berperilaku karena faktor keinginan, kesengajaan atau karena memang sudah direncanakan. Niat berperilaku (behavior intention) masih merupakan suatu keinginan atau rencana. Niat belum merupakan perilaku, sedangkan perilaku (behavior) adalah tindakan nyata yang dilakukan.

Komitmen yang tinggi untuk berperilaku tertentu, sesuai dengan rencana untuk meningkatkan kemampuan individu dapat mempertahankan perilaku promosi kesehatan tersebut sepanjang waktu (Pander, N.J, Murdaugh, C.L., \& Parsons, M.A dalam Alligood \& Tomey, (2006)). Pendidikan 
mempengaruhi proses belajar, semakin tinggi pendidikan seseorang semakin mudah dalam menerima informasi, baik dari orang lain maupun dari media masa. semakin banyak informasi yang masuk maka akan semakin luas kekayaan pengetahuan yang diterima tentang program imunisasi (Notoatmodjo, 2012).

\section{Perbedaan Komitmen orang tua sebelum dan sesudah pemberian pendidikan kesehatan}

Hasil Penelitian menunjukkan bahwa frekuensi tertinggi komitmen sebelum dilakukan pendidikan kesehatan sebagian besar memiliki komitmen baik sedangkan frekuensi tertinggi komitmen ibu sesudah dilakukan pendidikan kesehatan hampir seluruhnya adalah baik (93,3 $\%)$. Berdasarkan uji statistik dengan menggunakan uji Wilcoxon diperoleh hasil negative ranks yaitu $\mathrm{N}=0$ yang berarti tidak ada penurunan komitmen sesudah dilakukan pendidikan kesehatan sedangkan pada positive ranks didapatkan nilai $\mathrm{N}=29$ yang berarti 29 responden mengalami peningkatan komitmen sesudah dilakukan pendidikan kesehatan, dan hanya satu orang yang nilainya tetap, karena meskipun terjadi perubahan nilai pada skor kuesioner namun total kuesioner responden tetap pada kategori cukup.Dari hasil uji statistik juga diperoleh nilai $\mathrm{p}=0,000$ sehingga $\mathrm{p}$ value $<\alpha=0,05$ sehingga $\mathrm{H} 1$ diterima yang berarti ada perbedaan komitmen ibu sebelum dan sesudah pemberian pendidikan kesehatan dengan pendekatan Nola J., Pander.

Program Imunisasi bukanlah program yang baru bagi masyarakat Indonesia sehingga komitmen baik untuk melakukan imunisasi sudah tampak bahkan sebelum dilakukan pendidikan kesehatan, hal ini terbukti dari hasil penelirtian yang menyebutkan bahwa sebagian besar komitmen ibu sudah baik sebelum pemberian pendidikan kesehatan, hal ini tidak dapat terlepas dari peran tenaga kesehatan setempat dalam mensosialisasikan program imunisasi yang ada, namun demikian dapat dilihat dari hasil penelitian bahwa pemberian pendidikan kesehatan meningkatkan kognisi ibu tentang manfaaat DPT 2 sehingga berdampak pula pada komitmen ibu untuk mengimunisasikan anaknya.

Komitmen seseorang dalam melakukan tindakan pencegahan dapat dipengaruhi oleh faktor, pendidikan dan pengetahuan. Tingkat pendidikan responden yang tinggi namun memiliki pengetahuan yang kurang tentang imunisasi disertai dengan adanya pengalaman atau efek dari imunisasi telah menjadi faktor yang menyebabkan rendahnya komitmen responden dalam merencanakan tindakan pencegahan penyakit.

Oleh sebab itu pendidikan kesehatan dengan pendekatan model Nola J. pander memberi dampak pada perubahan kognisi responden yang akhirnya membawa perubahan pada pemahaman dan komitmen responden terhadap tindakan pemberian imunisasi DPT2. Keadaan ini sesuai dengan pendapat Pander, N.J, Murdaugh, C.L., \& Parsons, M.A dalam Alligood \& Tomey, (2006) yang mengemukakan bahwa professional kesehatan merupakan bagian dari lingkungan interpersonal yang memberikan pengaruh pada orang-orang sepanjang masa hidup mereka. Tentunya seseorang dapat memodifikasi

pengetahuan, 
interpersonal dan lingkungan fisiknya yang mendorong melakukan perilaku atau tindakan kesehatan.

Hal ini didukung oleh Aisyah (2010) Health Promotion Model dikembangkan oleh Nola J Pander yang berlatar belakang dari keperawatan, pembangunan manusia, psikologi eksperimental, dan pendidikan membimbingnya untuk menggunakan perspektif holistik keperawatan, psikologi sosial, dan teori learning sebagai dasar. Pada teori HPM adanya suatu perubahan perilaku dikarenakan dipicu oleh adanya komitmen individu untuk merencanakan dalam suatu tindakan (Pander, N.J, Murdaugh, C.L., \& Parsons, M.A dalam Alligood \& Tomey, (2006)). Komitmen untuk merencanakan suatu tindakan adalah strategi tertentu untuk mendapatkan, melaksanakan atau penguatan terhadap suatu tindakan yang akan dilakukan ,oleh sebab itulah kenapa model ini memberikan dampak yang signifikan terhadap perubahan komitmen ibu.

\section{KESIMPULAN}

a. Sebagian besar ibu memiliki komitmen yang baik sebelum dilakukan pendidikan kesehatan dengan pendekatan Nola J. Pander di Puskesmas Burneh

b. Hampir seluruh ibu memiliki komitmen yang baik sesudah dilakukan pendidikan kesehatan dengan pendekatan Nola J. Pander di Puskesmas Burneh

c. Terdapat perbedaan komitmen ibu sebelum dan sesudah dilakukan pemberian pendidikan kesehatan dengan pendekatan model Nola J. Pander di Puskesmas Burneh

\section{DAFTAR PUSTAKA}

Alligood, M.R. \& Tomey, A.N. (2006). Nursing Theorist and their work. 6th Edition, ST. Louis: Mosby Elsevier, Inc

Aisyah. (2010). Pengaruh pemberian paket pendidikan kesehatan perawatan ibu nifas (PK-PIN) yang dimodifikasi terhadap pengetahuan, sikap, dan perilaku ibu postpartum primipara dalam merawat diri di Palembang. (Tesis) Jakarta: Universitas Indonesia

Achmadi, 2006. Imunisasi Mengapa Perlu? Cetakan I, Penerbit Karya, Jakarta

Depkes RI. 2013. Riset Kesehatan Dasar. Jakarta: Badan Penelitian dan pengembangan Kesehatan Kementrian Kesehatan RI.

Deslidel. (2011).Buku Ajar Asuhan Neonatus Bayi Dan Balita. Jakarta: EGC

Dinas Kabupaten Bangkalan. (2017). Profil Dinas Kesehatan Kabupaten Bangkalan

Kemenkes RI. Profil Kesehatan Indonesia. Jakarta: Kementrian Kesehatan Republik Indonesia, 2014

Notoatmodjo, (2012). Promosi KesehatanDan Ilmu Perilaku. Jakarta :Rineka Cipta 
Potter Perry (2009). Fundamental of Nursing,Buku 1, Edisi : 7, Salemba Medika :Jakarta

Susilo (2011). Pendidikan kesehatan dalam keperawatan. Yogyakarta : Nuha Medika

Rahmawati A I, Umbul C.(2012) Faktor yang mempengaruhi kelengkapan imunisasi dasar diKelurahan Krembangan Utara. Jurnal Berkala Epidemiologi

World Health Organization. (2012). World Health Statistics. http://www.who.int/gho/publi cations/world_health_statistic s/2012/en/ Diunduh tanggal 20 Oktober 2017 